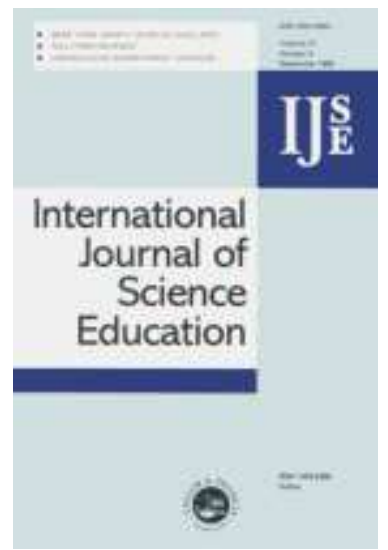

The use of newspaper articles as a tool to develop critical thinking in science classes

\begin{tabular}{|r|l|}
\hline Journal: & International Journal of Science Education \\
\hline Manuscript ID: & TSED-2010-0423-A.R1 \\
\hline Manuscript Type: & Research Paper \\
\hline Keywords: & secondary school, scientific literacy \\
\hline Keywords (user): & Critical thinking, newspaper critical reading \\
\hline \multicolumn{2}{|l}{} \\
\hline
\end{tabular}

SCHOLARONE $^{\text {m }}$

Manuscripts

URL: http://mc.manuscriptcentral.com/tsed Email: editor_ijse@hotmail.co.uk 


\section{The use of newspaper articles as a tool to develop critical thinking in science classes}

\section{Introduction}

Reading is a fundamental process in science learning since it is not only one of the most often used resources during the school years but can also become a basic tool for ongoing learning throughout life. The media and particularly the written press provide the main sources of scientific information for most adults (Jarman \& McClune, 2002; Korpan et al, 1997). In these media, opinions are often based on scientific knowledge which the reader needs to know in order to be able to make a critical analysis. This information can influence what people believe and how they behave, consequently, competence in evaluating media reports of science is important (Norris et al, 2003). Understanding and evaluating reports of science in newspapers is frequently included in the literature as an attribute of a scientifically literate person (Korpan et al, 1997; Wellington, 1991).

Research has been done on how to teach and learn about science news, some of which focuses on students, analysing their perceptions and understanding of science from newspapers (Halkia \& Mantzouridis, 2005; Korpan et al., 1997; Norris et al., 2003; Phillips \& Norris, 1999; Ratcliffe \& Grace, 2003; Ratcliffe, 1999) and other research is based on teachers, their perceptions and use of newspapers (McClune \& Jarman, 2010). Research in the UK at least suggests that science teachers frequently use news reports in the classroom, but often 
simply to emphasise the relevance of science in everyday life (Halkia \& Mantzouridis, 2005; McClune \& Jarman, 2010).

The aim of this research is to provide an in-depth analysis of the difficulties experienced by students at two schools with the critical reading of two newspaper articles with scientific content and, for this purpose, we designed an instrument to rank the students' responses to each of the "Elements of Science Critical Reading".

\section{What is meant by critical reading?}

Students believe that "reading is being able to say the words correctly" (Baker \& Brown, 1984) and, generally, scientific texts are presented to them as a tool for acquiring knowledge that they have to store in their memories. However, according to Olson (1994), reading should be seen as an active process involving the construction of meaning based on the text, whereby the reader consciously makes three different worlds interact: the world of the reader made up of his or her knowledge, beliefs or emotions, the world on paper defined in the text and the outside world. This means that the meaning of the text is not contained in the text itself but that readers have to construct the meaning using their own references. Therefore, reading depends on readers' prior knowledge and requires them to contextualise and infer the writer's intentions and actively construct new knowledge (Yore, Craig \& Maguire, 1998).

Readers can take different epistemological positions with respect to a text. In this study, we are interested in the critical position, whereby the reader starts an interactive relationship between the text and his or her beliefs or opinions in order to obtain the most consistent and complete interpretation possible, while 
still taking into account his or her previous ideas and the information contained in the text. Therefore, in order to be a competent reader, it is not sufficient to be capable of reading and understanding a text, but it is also necessary to be able to read it critically and, to infer, for example, whether the data and arguments it contains are credible. Reading means understanding, interpreting, analysing and criticising texts. This is the basic meaning of literacy (Norris \& Phillips, 2003).

However, we should not forget that the text is a cultural instrument with values situated in a particular time in history. In other words, its author is not a neutral person but someone with knowledge, a culture and intentions that are reflected in the text and that the reader needs to interpret. Knowledge is always contextualised and readers construct their interpretations based on their community and culture. Critical reading and, therefore critical thinking, depend on the context and culture in which they are situated (Pithers \& Soden, 2000).

The ability to analyse texts and the data and arguments they provide critically and to justify one's own point of view requires the development of critical thinking, an area in which research is being carried out from various perspectives (Ennis, 1996; Paul \& Elder, 2006; Phillips \& Norris, 1999; Ten Dam \& Volman, 2004; Zoller et al, 2000).

There has been much debate on the question 'What is critical thinking?' (Kennedy et al., 1991). There is currently considerable consensus concerning the perception of critical thinking as being a combination of abilities and dispositions (Ennis, 1996; Ten Dam \& Volman , 2004). The abilities are the 
cognitive element, knowing what to do and the dispositions are the students' attitudes or predispositions towards critical thinking.

In this research we have focused on assessing critical thinking abilities based on the proposal by Paul \& Elder (2006). These authors refer to thinking abilities as "Elements of Reasoning" (see Table 1).

We would agree with Zoller et al. (2000) that the most important aim in science education is to develop students' thinking abilities within the specific context of science. There is a consensus that in order to promote critical thinking attention must be focused on developing students' epistemological beliefs, enabling active learning using problems relating to real-life situations and encouraging interaction between students to enable them to talk and share different viewpoints. All this necessarily implies a new way of working in the classroom. Students must be given time to approach problems, to form good questions, consider hypotheses and thereby formulate good arguments (Izquierdo, 2004). Therefore, we believe that the working methodology used by teachers plays an essential role in developing critical thinking among students. If teachers think students learn exclusively through the transmission of information from the teacher to the students, it is quite likely that they will not invest any time in encouraging cooperational work and the exchange of ideas between peers.

On the other hand, teachers who believe that discussing and thinking about problems promotes students' intellectual development and a greater understanding of scientific ideas, will encourage discussion between peers and between the students and the teacher, thereby establishing meaning making 
interactions (Scott, Mortimer \& Aguiar 2006). These teachers engage their students in the language of thinking.

Based on this perspective, we believe it is very important to work on critical thinking in science classes but as Dreyfus \& Jungwirth (1980) noted, students find it difficult to transfer it to real contexts. Therefore, we see the need to apply critical thinking to real issues. Reading newspaper articles could be a means to help students to apply critical thinking to their day-to-day lives.

\section{Critical reading of newspaper texts with scientific content}

It is important to note that the science written about in newspapers or other sources (the internet, magazines, etc.) is very different to the science written about in an academic context. The purpose of the scientific news stories that appear in the press is to communicate but not teach science. Different types of articles with a scientific context can be found in the press depending on whether it is their purpose to provide scientific information, explain problems arising in connection with science or to use scientific arguments to back up ideas to be defended or discussed. In our research the texts worked on fell into the last category. This type of article can be found in daily newspapers (where the source is easily identified) but also in any search of the internet, which makes it more difficult to ascertain the author. Critical thinking about science in the news requires an understanding of science but it also requires a degree of media awareness. (Jarman \& McClune, 2007; McClune \& Jarman, 2010, Jarman and McClune, 2010). Therefore, we have to help students to understand that science in the news and other sources of information (the internet) have significant strengths as well as limitations as sources of information and 
recognise the key role of news media in flagging up developments in science and socio-scientific issues.

Bearing in mind that the main purpose of the press is communication, it is logical for newspaper articles about science to contain very little specialised information as that would impede communication. This can make it difficult to read articles on science from sources not directly designed for teaching the subject. Scientific facts can be found in newspapers but the evidence for such facts cannot always be found, nor is it possible to recognise the theoretical model used as a basis (Martins et al., 2001; Márquez \& Prat, 2005). Accordingly, in order to perform a critical interpretation of newspaper articles with scientific content, students must be able to activate the scientific knowledge learnt at school and, clearly, that is not an easy connection to make but one that needs to be learned, which we believe has to be done in science class. Therefore, in order for students to be able to read newspaper articles with scientific content, the science curricula used in schools must provide sufficient scientific knowledge and be meaningful (Millar, 2006). The point is not so much to transmit a lot of information but to promote the construction of general and abstract theoretical models which can potentially be used to interpret very varied facts and analyse subjects which do not form the hard core of science (Duschl, 1990).

Each discipline provides theoretical models of reference to analyse phenomena and problems and without them it is difficult to be able to think critically. Therefore we would agree with Brown (1997) when he says that critical thought must be developed in the context of a specific discipline and in relation to situations and problems connected to daily life, which are what many 
newspaper articles discuss. Their function is to motivate and give meaning to learning (Ten Dam \& Volman, 2004), but more specifically, they are important for promoting the development of critical thinking and recognising how science is used to argue points of view (Kennedy et al., 1991; Oliveras \& Sanmartí, 2009).

When students read about science-related ideas, advances, issues or problems they must be able to establish connections between their knowledge of science and the content of the reading, so that they are able to understand the text and analyse it critically (while learning about science). Establishing these connections requires learning to be based on activities designed for this purpose and help from the teacher to ensure that students are able to activate the scientific model implicit in the text as well as the elements enabling them to carry out a critical reading.

One of the tools for promoting critical reading is proposed by Bartz (2002) in the form of the C.R.I.T.I.C acronym. According to the author, the letters of the acronym represent the concepts that constitute critical reading. Each letter represents a task, in the form of a question that the student reader has to consider in order to apply critical thinking to his or her reading (see first column, table 1).

Similarities can be found between the questions included in the C.R.I.T.I.C questionnaire applied to the reading of texts and the first seven reasoning elements of Paul \& Elder (2006). Based on these two approaches, we identified certain "Elements of science critical reading" that we considered useful to guide the critical reading of newspaper articles with scientific content and also to 
analyse students' difficulties. The eighth element of reasoning of Paul and Elder (Implications \& Consequences) was not included in this research study as an "Element of science critical reading", given the characteristics of the articles and the fact that the purpose of the classroom work was geared towards a critical analysis of the scientifically based arguments used in the texts rather than proposing discussions and consequences. However, we consider that the eighth element of reasoning of Paul and Elder to be essential. Discussing with students the 'implications and consequences' for them, their families, their friends and their communities of science issues reported in the news is a very important aspect of a science education that aims to promote 'scientific literacy'.

Table 1 shows the "Elements of science critical Reading" extracted from the two approaches and contains examples of the question types included in the activities designed as part of this research study. A basic element in the critical reading of science articles is identifying the writer's purpose, his or her ideas and the assumptions he or she made when writing the text. In this regard, the "Elements of science critical reading" were defined with elements 2, 3 and 4 aiming to encourage students to think of the writer's "Purpose", "Point of view", "Assumptions" and "Questions".

(Insert Table 1)

In the design and application of the activities to promote critical reading, the questions posed are important as are other methodological strategies. Among these strategies we consider those related to cooperational learning and group discussion to be essential as they improve the comprehension of texts (Dansereau, 1987) as well as critical reading (Márquez \& Prat, 2005; Oliveras \& 
Sanmartí, 2009; Paul, 1992), while also encouraging the development of thinking abilities (Hager et al., 2003).

\section{Objectives of the research}

The specific objectives of the research are as follows:

1) To analyse students' difficulties in applying the "Elements of science critical Reading" defined in the reading of press articles.

2) Identify how the content of the readings and the types of questions raised in the activities affect the students' answers.

\section{Project description}

a) Selection of articles

Two newspaper texts with scientific content were selected ${ }^{1}$. These texts were chosen according to the theoretical models recently worked on at the sample schools and the interest they could awaken in the students (15 years old). The aim was to detect whether the students could apply the scientific knowledge they had learnt in the classroom to the analysis and interpretation of real current problems. The articles selected were included in the features section of the newspaper and were not aimed at providing scientific information, but used scientifically based arguments to back up statements or discuss issues surrounding a current event.

The subject of the graffiti article was the difficulty involved in removing graffiti on glass. According to the author of the news report, graffiti on glass is so difficult to remove because graffiti writers mix acid with the paints they use. The news story was chosen so that the students could apply their knowledge of chemical 
change. Since the information in the text was not completely correct, because acids (apart from hydrofluoric acid) do not react with glass, the students were able to question the scientific basis of the news story.

The swimsuit article contained opinions for and against whether the swimsuits used by swimmers had helped improve the latest Olympic records. The news story was chosen so that the students could apply their knowledge of cynematics and dynamics to the analysis of an actual event.

b) Subject Selection or Research population

The research was conducted in two secondary schools in Catalonia (Spain). School 1 is situated in Barcelona and its students come from a low social and economic bracket, with $30 \%$ of them being immigrants. School 2 is in a town, near Barcelona with a population of 4,000 and its students are from a medium to high social and cultural bracket, with $9 \%$ being immigrants. A total of 61 students took part (15 to 16 years of age), 30 in school 1 and 31 in school 2. They were from four different classes ( 2 per school). The two activities were applied in both the schools, one in each class, and therefore each student only carried out one activity. The four classes were given by four different teachers and contained around 12 to 20 students.

The two schools were characterised by the importance placed on experimental work. The activities were presented to the teachers of the classes involved in the research at a meeting. It should be noted that these types of activities had never been conducted in any of the science classes and, therefore, this was something new for the teachers and students involved. The methodology for application in the classroom was discussed in detail with the teachers involved. 
The expectation was that the activity would be approached as just another class task and had to be conducted in cooperative groups of four students grouped on an assorted basis.

Each teacher then conducted the activity in her class and collected all the written work generated by the students throughout the activity. This written work formed the basis of the data used to analyse the results.

c) Critical reading activities designed

To encourage critical reading of the articles and reflection, critical reading activities were proposed which included questions relating to those shown in Table 1.

The activities were designed taking into account the three phases of the reading process (before reading, during reading and after reading). In the first phase (before reading) the students' preliminary ideas on the key information in the lead paragraph and the scientific knowledge were activated. The questions proposed to activate these ideas were: "Read the title and look at the picture: What do you think the news story is about? Which newspaper was it published in? Who wrote it? Why are we reading this text in science class? What scientific content could the text relate to?". The students replied first individually and then discussed the questions in a large group.

In the second phase (during reading) the emphasis was placed on regulating the reading process. The students in groups of four were encouraged to help each other identify the problem posed by the writer, his or her intentions and the evidence and arguments he or she used. They also discussed specific sentences from the text and analysed the different viewpoints. The students 
answered the questions relating to elements 1 to 5 (Table 1). The questions were the same in the two activities apart from those relating to element 4 ("formulate a scientific question or experiment"), due to the difference in the scientific content of the texts.

Specifically, in the text on graffiti activity, the students were asked to formulate a scientific question to be researched. On the other hand, in the activity on swimsuit activity, the question was already posed in the text and the students were asked to design a scientific experiment to demonstrate it.

The third phase (after reading) was designed for the students to assess the scientific basis for the news stories and draw up a text arguing their viewpoint. Before writing the final discussion text the students had to answer a series of questions to think about the science model implicit in the text and discuss the problems it raised, first in small groups and then with the whole class. The questions aimed at thinking about the scientific model were different in each activity.

(Insert Figure 1).

Once the students had agreed on the problem to be investigated in depth by the whole group/class, the students looked up information on the internet to resolve any questions that had arisen or to validate any ideas they had discussed or the data provided. It should be noted that in previous sessions, the students had worked on the credibility criteria required to analyse websites. Using the researched information, the students thought about and connected various arguments or scientific ideas and constructed their own lines of argument. 
With this information the students had to write a text, validating or criticising the scientific content of the news story in the case of the activity on graffiti or taking a stance on whether the new swimsuits contributed towards improving swimmers' speed (see Table 1). They wrote the text based on guidelines encouraging them to consider their idea, formulate reasons supporting it and think of possible arguments against their idea and the evidence they could use to convince others (Osborne et al., 2004).

The activities lasted for five hours plus the homework and were carried out in February 2009.

\section{Data analysis}

Based on the "Elements of critical reading" we defined six categories used to analyse the data collected in this study. A table was drawn up with an assessment scale of 1 to 5 for each category. The scale was defined on the basis of the scale proposed by Paul \& Elder (2005) to rank the levels of critical reasoning but it was modified according to what the students had written in their attempt at critical reading.

The scale and the classification of the students' answers were validated by two experienced teachers. These teachers are experts in applying innovative science teaching projects and in research, particularly in the field of relationships between language and science learning. This scale is shown in Table 2.

(Insert Table 2) 
To analyse the results relating to the first five categories, the data collected from the students' answers to the tasks performed during the pre-reading and reading phase were used. On the other hand, the results relating to category 6 were obtained in the after reading phase when the students had reformulated the problem and researched information to support their ideas.

\section{Results and Discussion}

The average scores in each category between the two schools and the two activities were compared, together with the interaction between them, using a two-way analysis of variance (ANOVA). All statistical tests were assessed as significant when the $p$ values obtained were less than 0.05 .

The students who did not answer the questions were considered lost values in the analysis.

The research results were organised by objective.

Objective 1: To analyse students' difficulties in applying the "Elements of science critical Reading" defined in the reading of press articles.

To achieve objective 1 of the research we focused on the means in each category. The results (see Figure 2) show that category 2 (identify the writer's purpose) and category 5 (identify data and evidence given in the text) were those that students found the most difficult overall.

(Insert Figure 2)

There were various answers to the question "Why must he or she have written it?" relating to category 2 (table 2). We set out below an example of each level of the scale (1-5) which can relate to both activities 1 -graffiti or - swimsuit: 
"because he/she was affected" (level 1, graffiti) ,"they want to detract from the Olympic records" (level 2, swimsuits), "to inform people" (level 3)(swimsuits and graffiti), "to show people the consequences of graffiti" (level 4, graffiti), "to provide information on the reasons for the controversy surrounding these swimsuits" (level 5, swimsuits).

It should be noted that most students chose level 3. In relation to this category the results can be explained by the fact that most of the students were convinced that the purpose of the text was to inform and that this information is always neutral and unbiased. Few students went any further than merely stating that the intention was just to inform and could not think of any possible reasons why this information was given, such as to create controversy or convince readers to use certain swimsuits or brands. Therefore, the most frequent answers were of the following type: "To inform about a news event that has taken place".

With respect to category 5, there were different answers, although most related to lower levels $(1,2)$. In the graffiti activity there were no level 4 or 5 answers. Some examples are shown below:

"We think it has a scientific basis because it is in the newspaper" (level 1, graffiti)", "I think that he/she has obtained information from the clean-up squad" (level 2, graffiti), "It certainly has a scientific basis as the writer has investigated and taken samples of the graffiti and analysed it" (level 3, graffiti), "There are patches that help swimmers to float and they have an influence in races where floatability is important. Because there is less friction, speed is increased" (level 4, swimsuits), "There is no evidence because these are only opinions from 
people. I think that other arguments and tests would be required to make it really scientific" (level 5, swimsuits).

With respect to category 5 , the difficulties detected related to the assumption by the students that a journalist is an informed and qualified person. If, in addition, the text contained a word that they considered to be scientific (acid, floatability, concentration, etc.), they considered this to be a sufficient indicator to support the scientific basis of the news story and, therefore, they saw it as proof of what the writer said.

Category 6 (draw conclusions from the evidence) obtained the best results. The ideas relating to this category pinpoint the students' critical thinking performance throughout the activity. This category appeared in the students' written work at the end of the activity and resulted from their thinking about the science model implicit in the text and comparing their own viewpoints with the information they had gathered. It was shown that, although the students first seemed convinced that the information given in the article was objective and did not question its scientific basis, in the end they were able to compare the world on paper with the reader's world (Olson, 1994), thereby becoming more critical of the content of the text. It could be stated that overall they learned something. It was seen that most of the students were able to read critically.

In the graffiti activity, the students mostly reached the conclusion that the information in the text was not completely accurate since most acids do not react with glass and, in any case, only some specific acids, such as hydrofluoric acid, should have been mentioned. Although at first they were not sure whether the problem was due to the fact that there were types of glass with different 
properties or acids that did attack glass, after consulting the internet, they were able to decide. They were therefore able to judge the scientific basis of the reading. This can be seen in this example relating to level 5 "To the editor of "La Vanguardia" newspaper. I am writing concerning an article you published on graffiti. I have been researching information and it is not true that the problem is due to the reaction between glass and a mixture of acids and tar, since only one acid reacts with glass (hydrofluoric acid) and not all, or practically all, acids, as the author stated.(...). We have looked at websites and found that there are other acids that react but they are not by knowledgeable people. If you do not believe us you can go to the website I have found which is from a reliable source. We could also obtain evidence by performing an experiment."

It should also be noted that there were students who were not able to make a critical reading and, in the end, they validated the information in the text, giving priority to the world on paper, even though they had found information on the internet that contradicted the scientific basis of the news story.

Some students, when asked to provide a critical viewpoint, did not fulfil this request but, instead, made an analysis based on whether they agreed with graffiti or not, or with the use of acids in graffiti. They had difficulties when it came to questioning the scientific basis for the story. In fact, they rewrote the information using their own knowledge and information they had found, without recognising that the writer did not say what they stated. This can be seen in this example relating to level 1 "The text has positive and negative aspects. It is true that the graffiti writers ruin glass, walls ... but if the graffiti writers had places to do their graffiti, this would not happen (...). In conclusion, in some ways the writer is right. It is dangerous for young people to mix acids with other 
substances and on some points I do not agree with the writer because I believe, for example, that graffiti writers should have somewhere to do their graffiti without anyone prohibiting them".

The same happened in the swimsuit activity. Most of the students were able to form an opinion on the information read and most of them gave scientific arguments as to why the swimsuits improved the swimmers' speed (level 5) "I think that the swimsuit helps you to float and because there is more floatability friction is reduced and speed increased. (...) . I would convince anyone who did not believe me by performing an experiment (...) using a robot resembling a person and giving it the same strength, I would put the Speedo swimsuit on it and then take it off. If the speed with the swimsuit is greater, then the swimsuit helps you to float".

On the other hand, some students, despite detecting that the swimsuits had special properties and characteristics, finally concluded that the swimsuits did not help improve speed. These students justified the records of the 2008 Olympic Games with arguments such as: the swimmer's efforts, his or her physical fitness and good training. Some students even talked about a good diet as an argument to justify the increase in Olympic records. They did not consider the variable mentioned in the article to be important: "I think that the swimsuits, of whatever brand, do not influence the result. The fabric used in the swimsuit must have properties that improve the swimsuit but do not improve speed. Each swimmer can have his or her favourite brand and think that that brand of swimsuit is ideal because it has given them a good record. However, in fact that is not the case. It is actually the swimmer's physical qualities that enable him or her to obtain this result (...)" (level 2). 
We consider that the ability to read science critically is shown in the results of category 6 -draw conclusions from the evidence- as this is when students show that they are capable of identifying the main scientific arguments given in a text, comparing them with those relating to the corresponding scientific theoretical model, the possible evidence obtained in experiments and/or reliable sources of information, and making a critical analysis of the contents of the text. This would be the difference between reading critically and reading science critically because the student is capable of identifying the essential ideas of a text, the evidence or scientific arguments and the writer's intentions, which would indicate a good level of reading comprehension but if the student does not compare the scientific arguments in the text with the corresponding theoretical models, the student is not necessarily reading science critically.

We believe the instrument designed for assessing the students' capacity for critical reading (see Table 2) to be effective as the 5 levels in each category include differentiated aspects which enabled us to encompass all the students' answers and therefore detect the specific difficulties shown by students in critical reading.

The instrument was useful for reading the two articles which are quite different and therefore it could be used to assess students' capacity for critical reading in other articles with scientific content.

Objective 2- Identify how the content of the readings and the types of questions raised in the activities affect the students' answers. The results of the activities carried out were compared according to the various categories (Table 3). (Insert table 3) 
The results show that there are significant differences in categories 4 and 5 , but not in the rest.

As for category 4, graffiti activity required the students to formulate a problem that could be scientifically investigated, without the text giving any clues. In contrast, in swimsuit activity the problem was presented and the students were asked to think of a scientific experiment to demonstrate whether or not the swimsuits contributed to improving swimmers' speed. As could be expected, the results showed that the students found it more difficult to think of problems that could be scientifically investigated than scientific experiments that could be performed to answer a question.

For example, when the students were asked in graffiti activity how they thought a scientist would consider the problem, they concentrated on the products used to write the graffiti and wrote sentences such as: "Find out the chemical composition of the spray paints" or "Study the characteristics of the acids". No students approached the problem by investigating how the different acids interacted with the glass. They merely concentrated on one of the variables to be researched and not on the interaction between the two. This difficulty can be interpreted as being due to the fact that the question was too broad and not focused enough and therefore the students replied from a very general perspective.

However, when they had to think of a scientific experiment, they were much more precise and some of the students made a connection between the two variables: type of swimsuit and speed. Most of the students concentrated on demonstrating that with the new swimsuits, the times were reduced: 
"The experiment would be for the same swimmer to swim $50 \mathrm{~m}$ in a conventional swimsuit and $50 \mathrm{~m}$ wearing the Speedo swimsuit, in the same conditions (same swimming pool, same venue, same water temperature ..) and calculate the best time".

It should be noted that not all the students realised the need to control the variables. Some did not specify where they would conduct the experiment and others talked about carrying out the experiment in different swimming pools or using different swimmers: "Put the Speedo swimsuit on one group of four people and then put a normal suit on another four. If the swimmers wearing the Speedo swimsuit are first then that means that the swimsuit improves swimming speed and if not, that it does not"

Category 5 was also very different in the two activities. It was shown that the information provided in the text had an influence on recognising the evidence. If the texts contained information with a scientific basis, the students who understood the scientific model then recognised it. On the other hand, students invented evidence or made unfounded assumptions since, initially, they were completely confident that the writer's statements were true. The text on graffiti did not explicitly include any arguments or information justifying why the graffiti writers used acids and the only proof given in the text was the difficulty in removing the graffiti. Despite the lack of arguments, all the students initially thought that the writer's statement was true and, therefore, the graffiti writers used paints mixed with acids of whichever type. Their arguments were presented using unfounded assumptions that they considered to be evidence: "I think that he or she has obtained information from the clean-up squad". 
In contrast, the text in Swimsuit activity contained sentences such as ("the new swimsuit helps you to float" or "it is of more benefit to larger people") which, although they were arguments given by a swimmer, had a scientific basis. The text also said that the swimsuit was made of neoprene and, given this information, it could be inferred that the material had other properties that helped reduce friction. It should be noted that the only proof given in the text was the large number of records that had recently been beaten. We saw that the students who had assimilated the scientific basis ("if friction is reduced, speed increases") were able to detect information in the text that confirmed their idea and provide arguments, even though they had problems making a distinction between data, opinions, scientific arguments or evidence (see Table 2). "The swimsuit helps you to float, it is elastic and helps you gain speed in the water. I think that they are valid from a scientific standpoint because that is what people who have tried the swimsuit say" (level 3).

Based on knowing that the material was neoprene, some students talked about how it was slippery and that the way it compressed the body smoothed out any irregularities in the swimmer's skin. Some students concentrated on floatability to argue the increase in speed. Other students mentioned the improved floatability as a cause for the increase in speed but did not know how to argue this and possibly the fact that they were unsure of the scientific idea could have led them to identify floatability as a relevant issue since it is one of the few scientific terms in the text. Some students justified that the Speedo swimsuit helped improve speed by arguing that the number of Olympic records had increased and, therefore, it could be said that they were able to identify a piece of evidence in the text. 


\section{Conclusions and implications}

The use of critical reading activities in the classroom improves the ability to read critically (see Figure 2, category 6). We believe that it is not sufficient merely to read texts in the classroom and then ask questions about their contents, but students also have to be helped to understand, assess and reflect on the contents of the texts in a critical manner and also to recognise that science journalism is a distinct genre. We think that the fact that the majority of the activity was carried out in groups could have contributed to a better analysis of and reflection on the tasks involved. There are numerous studies that show that students learn more effectively when there is active participation in the activity through discussion, dialogue and interaction (Alexander, 2008; Chi, 2009; Mercer \& Littleton, 2007).

The students' answers show that it is not easy to apply critical thinking to the analysis of texts. According to Phillips \& Norris (1999), most students accept at first sight the information contained in the text and implicitly trust the writers. We identified that there are aspects of critical thinking where students have greater difficulties: identifying the writer's purpose and looking for evidence in a text. We believe that by working on different critical reading activities with texts from various sources (internet, newspapers, magazines, etc.), students can develop this skill and learn to read between the lines. We have also observed the difficulty experienced by some students in connecting science at school with the science that they read about in the press as in most articles no evidence is provided and the scientific theoretical model on which an article may be based is not identified. This makes it difficult for students to pinpoint scientific evidence in the text. Therefore, before reading the text, it is important to work on the 
differences between data, opinion, scientific arguments and evidence, bearing in mind what each one means and thinking about how each one is obtained (Roberts \& Gott, 2006). Making a distinction between these concepts can help students to read more thoroughly and analyse the information better.

We agree with various authors that what has the most effect on improving students' critical thinking is what the teachers think teaching and learning science means (Zohar \& Schwartzer, 2005). It is a fact that teachers have not been trained in critical thinking and usually complain of the lack of time and resources to make it a part of class activities (Barnes, 2005). In this study we put forward a proposal for working critically with newspaper articles but we think that without a belief in the importance of class discussion (Márquez \& Prat, 2005; Paul, 1992; Ten Dam \& Volman, 2004) on the interpretation of facts with a scientific basis it is difficult for students to develop critical thinking. Authors such as Osborne (2010) and Hayes \& Devitt (2008) take the view that collaborative discourse between students represents the ideal means to help students improve the quality of their thinking, always taking into account that discussions need to be regulated and guided by the teacher.

We also detected significant differences in some categories depending on the activities involved, specifically in category 4 (formulate a scientific question or an experiment) and in category 5 (identify data, evidence and scientific arguments in the text). In relation to category 4 , the students had more difficulties formulating a scientific question relating to a subject than in designing a scientific experiment to verify specific information in the text, although some students also had problems with the control of variables. We think that more emphasis needs to be placed on formulating scientific questions in science 
classes (an area that is assessed in the PISA programme) (OECD, 2006), while helping students to think of all the variables to be taken into account, and encouraging them to reflect more on the conclusions of experiments in the lab and whether the conclusions comply with the objectives.

As for category 5 , if the text does not contain scientific arguments, data or evidence to support the information, the students make unfounded assumptions and consider them as such, since they are convinced that information always has a basis. This shows that there is a need to read texts from different sources (newspapers, science magazines, the internet, etc.) and work on identifying the data, evidence and scientific arguments they contain since this is what students will be reading throughout their lives.

Lastly, we would like to point out that the activities designed on the basis of the "Elements of science critical reading" (see Table 1) proved to be very useful, both in helping students to read critically and in motivating them to do so. Although this research did not include element of science critical reading number 7, "Implications and consequence", we consider it essential to introduce it as another element.

The scale based on the performance indicators of Paul \& Elder (2005) (table 2) was very useful for detecting where students' difficulties with critical reading lie. If we want to help students to be critical we have to think of the difficulties they may have and use them as a basis to work on. The various levels identified are a useful tool for describing the steps to be followed by students to reach the maximum level for each indicator, thereby developing their ability to read science critically. In this regard, we would encourage teachers to work on 
critical reading activities and use Table 2 to identify the difficulties and successes of their students and use this as a basis for helping students progress to higher levels.

We can conclude that the critical reading activities analysed helped to connect different concepts studied in science classes and apply them to the analysis of a real-life problem. We think it important to do this in the context of science classes aimed at teaching specific theoretical models as through a specific discipline teachers can provide the means for incorporating school science into daily life while encouraging critical thinking (Kennedy et al, 1991; Brown, 1997;). After carrying out the activities, the students asked to do more of them which means we can say that they encouraged an interest in reading current texts and analysing them critically. This suggests that students find this type of activity motivating (Nolen, 2003).

Lastly, it is important to state that the objectives associated with critical reading cannot be achieved in a single activity and, therefore, they must be included regularly throughout the students' school career.

${ }^{1}$ http://grupsderecerca.uab.cat/liec/content/use-newspaper-articles-tool-develop-criticalthinking-science-classes-bego\%C3\%B1-oliveras (The articles may be found at the above link)

Acknowledgements: Based on work supported by Spanish MCYT grant EDU-200913890-C02-02) and Catalan PRI 2009SGR1543. The authors thank the teachers and students involved in the research. 


\section{Reference}

Alexander, R.J. (2008). Towards Dialogic Teaching: rethinking classroom talk. York, Dialogos.

Baker, L., \& Brown, A. L. (1984). Metacognitive skills and reading. In P.D. Pearson (Eds.) Handbook of reading research (pp. 353-394). New York, Longman.

Barnes, A. (2005). Critical Thinking Revisited: Its Past, Present, and Future. New Directions for Community Colleges, 130, 5-13.

Bartz, W. R. (2002). Teaching Skepticism via the CRITIC Acronym and the Skeptical Inquirer. The Skeptical Inquirer, 26(5), 42-44.

Brown, A. (1997). Transforming schools into communities of thinking and learning about serious matters. American Psychologist, 52, 399-413.

Chi, M.T.H. (2009). Active-contructive-interactive: a conceptual framework for differentiating learning activities. Topics in Cognitive Science, 1, 73-105.

Dansereau, D. (1987).Transfer from cooperative to individual studying. Journal of Reading, 30, 7, 614-619.

Dreyfus, A., \& Jungwirth, E. (1980). A Comparison of the 'Prompting Effect' of Out-of-School with that of In-School Contexts on Certain Aspects of Critical Thinking. Eur. Journal of Science Education, 2(3), 301-310.

Duschl, R. (1990). Restructuring science education the importance of theories and their development. New York, Teachers College Press.

Ennis, R. H. (1996). Critical Thinking. New York, Prentice Hall. 
Hager, P., Sleet, R. J., Logan, P., \& Hooper, M. (2003). Teaching Critical

Thinking in Undergraduate Science Courses. Science \& Education,12, 303-313.

Halkia, Kr., \& Mantzouridis, D. (2005). Students'views and attitudes towards the communication code used in press articles about science. International Journal of Science Education, 27 (12), 1395-1141.

Hayes, K.D., \& Devitt, A. A. (2008). Classroom Discussions with Student-Led Feedback: a Useful Activity to Enhance Development of Critical Thinking Skills. Journal of Science Education Research, 7, 65-68.

Izquierdo, M. (2004). Un nuevo enfoque de la Enseñanza de la química: contextualizar y modelizar. The Journal of the Argentine Chemical Society, 92 (4/6), 115-136.

Jarman, R., \& McClune, B. (2002). A survey of the use of newspapers in science instruction by secondary teachers in Northern Ireland. International Journal of Science Education, 24(10), 997-1020.

Jarman, R., \& McClune, B. (2007). Developing scientific literacy: Using news media in the classroom. Maidenhead, UK: McGraw-Hill Education

Jarman, R., \& McClune, B. (2010). Developing students' ability to engage critically with science in the news: identifying elements of the 'media awareness' dimension. Curriculum Journal, 21(1) 47 - 64

Kennedy, M., Fisher, M. B., \& Ennis, R. H. (1991). Critical thinking: literature review and hended research. In L. Idol \& B. Fly Jones (Eds.) Educational values and cognitive instruction: Implications for reform (pp 11-40): New York, . Hillsdale 
Korpan, C. A., Bisanz, G. L., Bisanz, J. and Henderson, J. M. (1997). Assessing literacy in science: Evaluation of scientific news briefs. Science Education, 81, 515-532.

Márquez, C., Prat, A. (2005). Leer en clase de ciencias. Enseñanza de las Ciencias, 23(3), 431-440.

Martins, I., Mortimer, E., Osborne,J., Tsatarelis, Ch \& Jimenez-Aleixandre, P. (2001). Rethorics and Science Education. In A. Behrendt et al. (Eds.) Research in Science Education, Past, Present and Future (pp. 189-198). Netherlands: Kluwer Acadèmic.

McClune, B., \& Jarman, R. (2010). Critical Reading Science-Based News Reports: Establishing a knowledge, skills and attitudes framework. International Journal of Science Education, 1-26

Mercer, N., \& Littleton, K. (2007). Dialogue and the Development of Children's Thinking: A sociocultural approach. London, Routledge.

Millar, R. (2006). Twenty First Century Science: Insights from the design and implementation of a scientific literacy approach in school science. International Journal of Science Education, 28(13), 1499-1521.

Nolen, S.B. (2003). Learning environment, motivation, and achievement in high school science. Journal of research in science teaching, 40, 4 , 347 - 442.

Norris, S. P., Phillips, L.M., \& Korpan, C.A. (2003). University students' interpretation of media reports of science and its relationship to background knowledge, interest, and reading difficulty. Public Understanding of Science, 12 (2), 123-145. 
Norris, S. P., \& Phillips, L. M. (2003). How literacy in its fundamental sense is central to scientific literacy. Science Education, 87, 224-240.

OECD/PISA. (2006) . Assessing Scientific, Reading and Mathematical Literacy: A Framework.Paris, OECD Pub. Service, 2006.

Oliveras, B., \& Sanmartí, N. (2009). La lectura como medio para desarrollar el pensamiento crítico. Educación Química, 20(1), 233-245.

Olson, D. R. (1994). The world on paper. Cambridge, Cambridge University Press.

Osborne , J. (2010). Arguing to Learn in Science: The role of collaborative, critical discourse. Science, 328, 463-466.

Osborne, J. F., Erduran, S., \& Simon, S. (2004). Enhancing the Quality of Argument in School Science. Journal of Research in Science Teaching, 41(10), 994-1020.

Paul, R., \& Elder, L. (2006). The Miniature Guide to Critical Thinking Concepts and Tools, Foundation for critical thinking. Retrieved May 20, 2010 from http://www.criticalthinking.org/files/Concepts Tools.pdf

Paul, R., \& Elder, L. (2005). A Guide for Educators to Critical Thinking Competency Standards. Foundation for critical thinking. Retrieved May 20, 2010 from http://www.criticalthinking.org/TGS_files/SAMCT_competencies_2005.pdf 
Paul, R. (1992). Critical thinking: What every person needs to survive in a rapidly changing world. ( $2^{\text {nd }}$ revised ed.). Santa Rosa, CA: Foundation for Critical Thinking.

Phillips, L. M., \& Norris, S.P. (1999). Interpreting popular reports of science: what happens when the reader's world meets the world on paper?. International Journal of Science Education. 21(3), 317-327

Pithers, R. T., \& Soden, R. (2000). Critical thinking in education: a review. Educational Research, 42(3), 237-249

Ratcliffe, M.(1999). Evaluation of abilities in interpreting media reports of scientific research. International Journal of Science Education, 21(10), 10851099.

Ratcliffe, M. \& Grace, M. (2003). Science Education for Citizenship: Teaching Socio-scientific issue. Philadelphia, Open University Press

Roberts, R., \& Gott, R. (2006). The role of evidence in the new KS4 National Curriculum for England and the AQA specifications. School Science Review, 87.

Scott, P., Mortimer, E., \& Aguiar, O. (2006). The tension between authoritative and dialogic discourse: a fundamental characteristic of meaning making interactions in high school science lessons. Science Education, 90, 605-631.

Ten Dam, G., \& Volman, M. (2004). Critical thinking as a citizenship competence: teaching strategies. Learning \& Instruction, 14 (4), 359-379. Wellington, J. (1991). Newspaper science, school science: friends or enemies?. International Journal of Science Education, 13(4), 363-372. 
Yore, L. D., Craig, M. T., \& Maguire, T. O. (1998). Index of science reading awareness: An interactiveconstructive model, text verification, and grades 4-8 results. Journal of Research in Science Teaching, 35, 27-51.

Zohar, A., \& Schwartzer, N. (2005). Assessing Teachers' Pedagogical knowledge in the context of teaching higer-ordrer thinking. International Journal of Science Education, 27 (13), 1595-1620.

Zoller, U., Ben-Chaim, D., \& Ron, S. (2000). The disposition toward critical thinking of high school and university science students: an inter-intra IsraeliItalian Study. International Journal of Science Education, 22 (6), 571-582. 


\section{Table 1. "Elements of science critical reading"}

\begin{tabular}{|c|c|c|c|}
\hline $\begin{array}{l}\text { C.R.I.T.I.C. } \\
\text { Bartz (2002) }\end{array}$ & $\begin{array}{l}\text { "Elements of Reasoning" } \\
\text { Paul \& Elder (2006) }\end{array}$ & $\begin{array}{c}\text { "Elements of Science Critical } \\
\text { Reading" }\end{array}$ & $\begin{array}{l}\text { Examples of question types posed } \\
\text { in classroom activities }\end{array}$ \\
\hline $\begin{array}{l}\text { C [Claim?]: What is the Claim being } \\
\text { considered? }\end{array}$ & $\begin{array}{l}\text { All reasoning is expressed through, } \\
\text { and shaped by, concepts and Ideas }\end{array}$ & $\begin{array}{l}\text { 1. Identify the main ideas of the } \\
\text { text }\end{array}$ & $\begin{array}{l}\text {-What problem does the text } \\
\text { present? - What is the main idea? } \\
\text {-What scientific content could it } \\
\text { relate to? }\end{array}$ \\
\hline $\begin{array}{l}\mathrm{R} \text { [Role of the claim?]: Who is } \\
\text { making the claim and is there } \\
\text { something in it for them, e.g., } \\
\text { money, fame, power, influence, } \\
\text { publicity?.. }\end{array}$ & All reasoning has a purpose & 2. Identify the writer's purpose & $\begin{array}{l}\text {-Who wrote this document? } \\
\text {-Why must he or she have written } \\
\text { it? }\end{array}$ \\
\hline $\begin{array}{l}\text { I [Information backing the claim?]: Is } \\
\text { it public information that can readily } \\
\text { be verified? Who provided it? }\end{array}$ & $\begin{array}{l}\text { All reasoning is done from some } \\
\text { point of view }\end{array}$ & $\begin{array}{l}\text { 3. Identify the writer's } \\
\text { assumptions and viewpoints }\end{array}$ & $\begin{array}{l}\text {-What position do you think the } \\
\text { writer of the news story takes on this } \\
\text { issue. Write sentences from the text } \\
\text { that help to see the writer's opinion } \\
\text { and justify the answer } \\
\text { - What assumptions does the writer } \\
\text { make in the text? Are they } \\
\text { justifiable? }\end{array}$ \\
\hline $\begin{array}{l}\mathrm{T} \text { [Test?]: If there is some reason to } \\
\text { doubt the claim, how might we } \\
\text { design an adequate test? What } \\
\text { would provide rigorous conditions } \\
\text { that preclude uncontrolled variables, } \\
\text { systematic error, or cheating from } \\
\text { biasing the results? }\end{array}$ & $\begin{array}{l}\text { All reasoning is an attempt to } \\
\text { answer some question }\end{array}$ & $\begin{array}{l}\text { 4. Formulate a scientific question } \\
\text { which the writer answers in the } \\
\text { article or design a scientific } \\
\text { experiment to verify the } \\
\text { information in the text }\end{array}$ & $\begin{array}{l}\text {-Could an experiment or test be } \\
\text { carried out to verify the credibility of } \\
\text { the main assumption? (Swimsuits) } \\
\text { What question would a scientist ask } \\
\text { to investigate this problem? (graffiti) }\end{array}$ \\
\hline $\begin{array}{l}\text { I [Independent test?]: Has any } \\
\text { unbiased source actually carried out } \\
\text { a rigorous independent test of the } \\
\text { Claim and published the results, } \\
\text { ideally in a reputable, peer-reviewed } \\
\text { research Journal?.... }\end{array}$ & $\begin{array}{l}\text { All reasoning is based on } \\
\text { information. }\end{array}$ & $\begin{array}{l}\text { 5. Identify data and evidence } \\
\text { given in the text }\end{array}$ & $\begin{array}{l}\text { Are there any arguments or } \\
\text { scientific evidence in the text that } \\
\text { support the initial assumption? Write } \\
\text { them down. }\end{array}$ \\
\hline $\begin{array}{l}\text { C [Cause proposed?]: What is held } \\
\text { out as a causal explanation for the } \\
\text { Claim and is it consistent with the } \\
\text { physical laws of the universe? }\end{array}$ & $\begin{array}{l}\text { All reasoning contains inferences or } \\
\text { interpretations by which we draw } \\
\text { conclusions and give meaning to } \\
\text { data. }\end{array}$ & $\begin{array}{l}\text { 6. Draw conclusions based on the } \\
\text { evidence }\end{array}$ & $\begin{array}{l}\text { Are the conclusions in line with the } \\
\text { current scientific knowledge you } \\
\text { have? (Swimsuit) } \\
\text { Write a text validating or rejecting } \\
\text { the scientific information in the text } \\
\text { (graffiti) }\end{array}$ \\
\hline
\end{tabular}


Table 2. Scale based on the performance indicators of Paul \& Elder (2005)

Cat 2. Identification of the writer's purpose
1. They cite non-relevant information or do not reproduce the information.

2. They only identify one of the key ideas or concepts.

4. They express in their own words the most important information. They identify some of the key ideas and concepts used in a way showing understanding. They make connections between ideas.

5. They express in their own words the most important information in a way showing understanding. They identify all the key ideas and concepts used in a way showing understanding.
Cat 3. Identification of the writer's assumptions and viewpoints
1. They cite irrelevant information

2. The information they express cannot be inferred from the text.

3. They assume that news stories are only used to inform in a neutral and unbiased manner. They identify the writer's purpose but in a not very precise way because they do not express themselves well or because they are not specific enough.

5. They communicate the purpose that they believe the writer has well. They realise that the writer has other intentions besides providing information (creating controversy...)

1. They do not answer or cite irrelevant information or they do not identify the writer's viewpoint.

2. They make unreasonable assumptions based on evidence and do not identify the writer's viewpoint or justify the point of view expressed.

They cite sentences word for word from the text without inferring the writer's viewpoint

4. They make reasonable assumptions, identifying the author's viewpoint but they do not justify it

5. They make reasonable assumptions and identify and justify the writer's viewpoint based on the text.
Cat 4. Formulation of a scientific question which the writer answers (graffiti) or
Propose an experiment to verify the information in the text. (Swimsuit)

Cat 5. Identification of data and evidence given in the text
1. They pose questions that are not very coherent or propose irrelevant experiments.

2. They pose the question without being specific or perform experiments that are excessively general.

3. They ask questions which are not answered in the text or perform experiments aimed at merely understanding the reason behind the problem.

4. They formulate reasoned important questions from a science standpoint, only analysing one of the variables or perform an experiment for verification based on only one of the variables.

5. They formulate reasoned important questions from a science standpoint, analysing all of the variables to be taken into consideration, or perform an experiment for verification based on all the variables.

1. They validate the information due to their confidence in the newspaper (they do not judge the credibility of the source) or because they think that the writer is informed.

2. They cite information in the text with basic or imprecise reasoning or draw conclusions based on irrelevant information in the text or do not mention whether it is evidence or not.

3. They mention whether the text provides evidence or not, or whether the information it provides is scientifically valid without giving further explanation or giving very basic arguments or without looking for scientifically valid without giving further explanation or giving very basic arguments or without looking for an argument to validate the information in the text

4. They draw reasoned conclusions based on the information provided in the text (facts, data, evidence ...), without identifying the type of source (fact, opinion, scientific source...).

They distinguish between facts, scientific arguments and opinion in the text. They draw conclusions taking into account the information available and using sensible reasoning they demonstrate the ability to analyse and evaluate the information objectively.

Cat 6. Arguing conclusions based on evidence
They cite irrelevant arguments

They reach conclusions based on daily knowledge without activating scientific knowledge. They activate their knowledge of science and demonstrate the ability to argue agreement and disagreement, although they do not challenge their knowledge using information in the text. They challenge the information in the text using their scientific knowledge and show reasonable agreement and disagreement without giving explicit grounds.

5. They challenge the information in the text with their scientific knowledge, showing an ability to argue agreements and disagreements in a reasoned manner. 
Table 3: Means plus standard deviation for each activity $(\mathrm{N}=61)$

\section{Graffiti Activity Swimsuit activity $\quad$ p}

\begin{tabular}{llll}
\hline Cat 1 & $2.88 \pm 1.4$ & $2.81 \pm 1.2$ & 0.821 \\
\hline Cat 2 & $2.60 \pm 1.2$ & $2.31 \pm 1.1$ & 0.251 \\
\hline Cat 3 & $2.91 \pm 1.5$ & $3.24 \pm 1.2$ & 0.323 \\
\hline Cat 4 & $2.10 \pm 0.6$ & $3.11 \pm 1.4$ & $<0.05$ \\
\hline Cat 5 & $1.30 \pm 0.7$ & $3.04 \pm 0.7$ & $<0.001$ \\
\hline Cat 6 & $3.50 \pm 1.6$ & $3.25 \pm 1.7$ & 0.804 \\
\hline
\end{tabular}


Figure 1: Questions in the after reading phase aimed at identifying and applying the scientific model implicit in the texts

\section{Graffiti activity (graffiti on glass):}

- What is the problem posed by the writer in this article?

- How do you think that the writer knows that the cause of the problem is the acids mixed with the kerosene? Is it just a hypothesis or does it have a scientific basis?

- Do you think that the graffiti could be removed from the glass?

- What knowledge would we need to explain the problem?

- Which steps would you follow to explain the problem? Where would you look for the information?

- Follow these steps to help explain the problem posed:

a) Write down all the applications of glass.

b) Try and deduce the properties of glass based on this list.

c) How is it that glass has these properties?

d) Do these properties help you to know anything else about glass?

e) How do the acids interact with the glass? Do all the acids interact in the same way?

\section{Swimsuit activity (new swimsuits):}

-Discuss these two sentences from the text. What do they mean?

- $\quad$ The new swimsuit helps you to float

- $\quad$ The new swimsuit is of more benefit to large people.

-Make a list of the properties a swimsuit must have in order to improve swimmers' speed (think of the design, the material.....). 
Figure 2. Average scores in each category (cat1-cat 5 before reading, during reading), cat6: after reading)

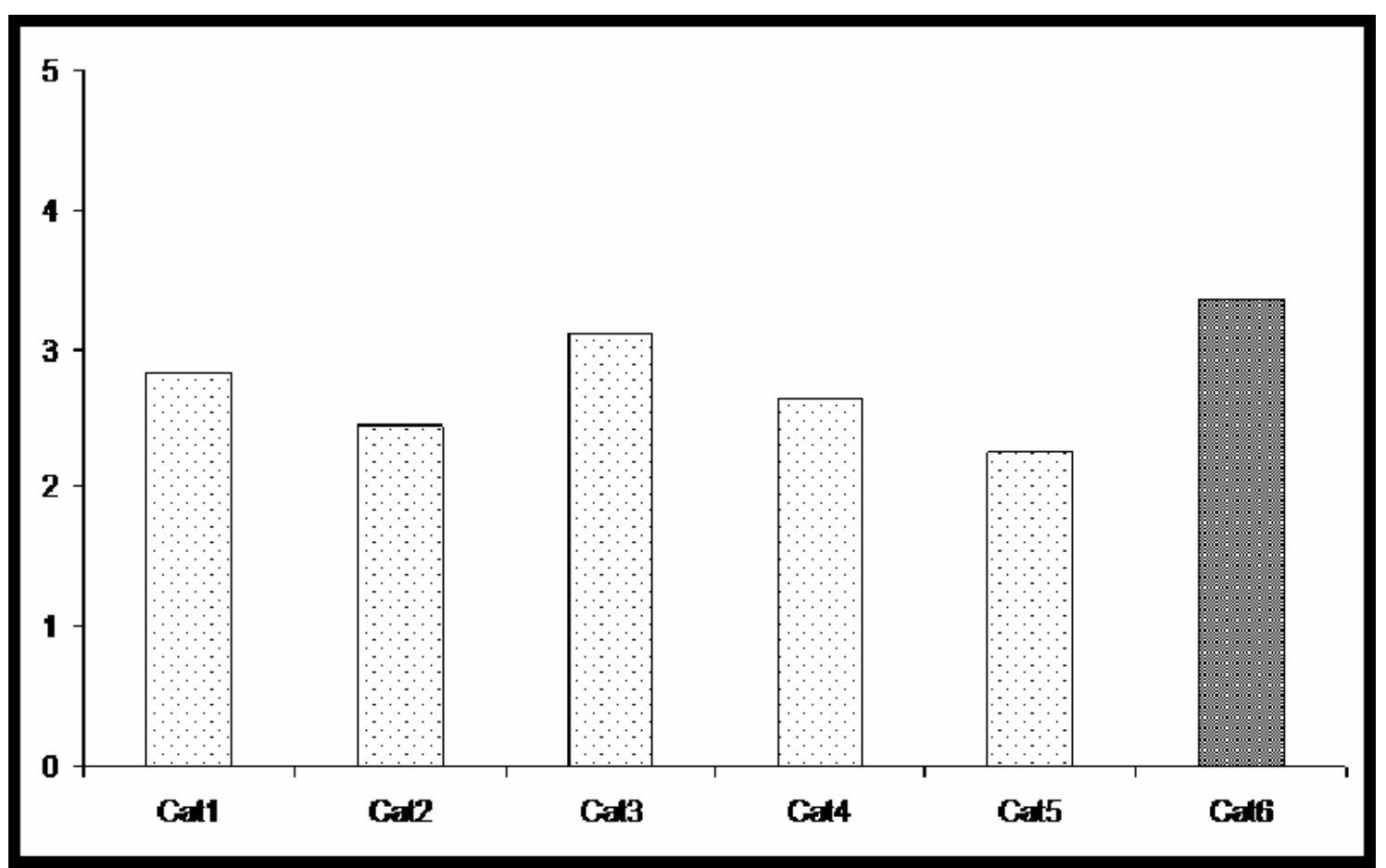

